\title{
Water under pressure
}

\section{A UN analysis sets out global water-management concerns ahead of Earth Summit.}

\section{BY NATASHA GILBERT}

$\mathrm{W}$ ater should be at the top of the agenda for the Earth Summit in Rio de Janeiro, Brazil, in June, a United Nations report urges.

The fourth World Water Development Report by the UN Educational, Scientific and Cultural Organization (UNESCO), launched at the World Water Forum in Marseilles, France, on 12 March, notes that industry, agriculture and booming urban populations are putting Earth's water supplies under unprecedented pressure (see graphic). Hundreds of millions of people do not have access to clean water, leaving them at risk from waterborne diseases. Without prompt action to improve water-management policies, the report says, a global crisis looms.

Although the document contains a plethora of facts and figures, its authors argue that a lack of reliable data on water quality and usage has become a stumbling block for efforts to strengthen policies and enforce regulations. "You cannot properly manage something that you don't know about," says Olcay Ünver, coordinator of the UN World Water Assessment Programme. But closing the knowledge gap will be expensive: building a gauging station to measure a river's flow can cost more than US $\$ 1$ million, for example, and the expense of ongoing operation can be difficult for poor countries to justify. The report recommends increasing the use of remote-sensing technologies to monitor water quality, but notes that these will never completely replace information gathered on the ground.

The report also focuses on the burgeoning demands of agriculture. Food production already consumes more than two-thirds of the world's extracted water, and food demand is expected to rise by $70 \%$ by 2050 , owing to population growth. Research into improving crop yields and drought tolerance will help nations to meet needs while using water more efficiently.

The report concludes that policy-makers must balance the requirements of agriculture and industry with the need for sustainable sources of clean drinking water by developing integrated policies that satisfy all three sectors. Michel Jarraud, chairman of UN-Water - a grouping of $28 \mathrm{UN}$ organizations including UNESCO - says that the group will tell leaders at the Rio summit that "the challenges, risks and uncertainties blocking the road to sustainable development require a collective response by the whole international community".

\section{WORLD'S THIRSTIEST}

Just three nations - India, China and the United States - together use about one-third of the roughly $4,000 \mathrm{~km}^{3}$ of water extracted globally each year. In general, water demands in developed countries have been declining during the past 20 years, mostly as a result of more efficient use of water resources.
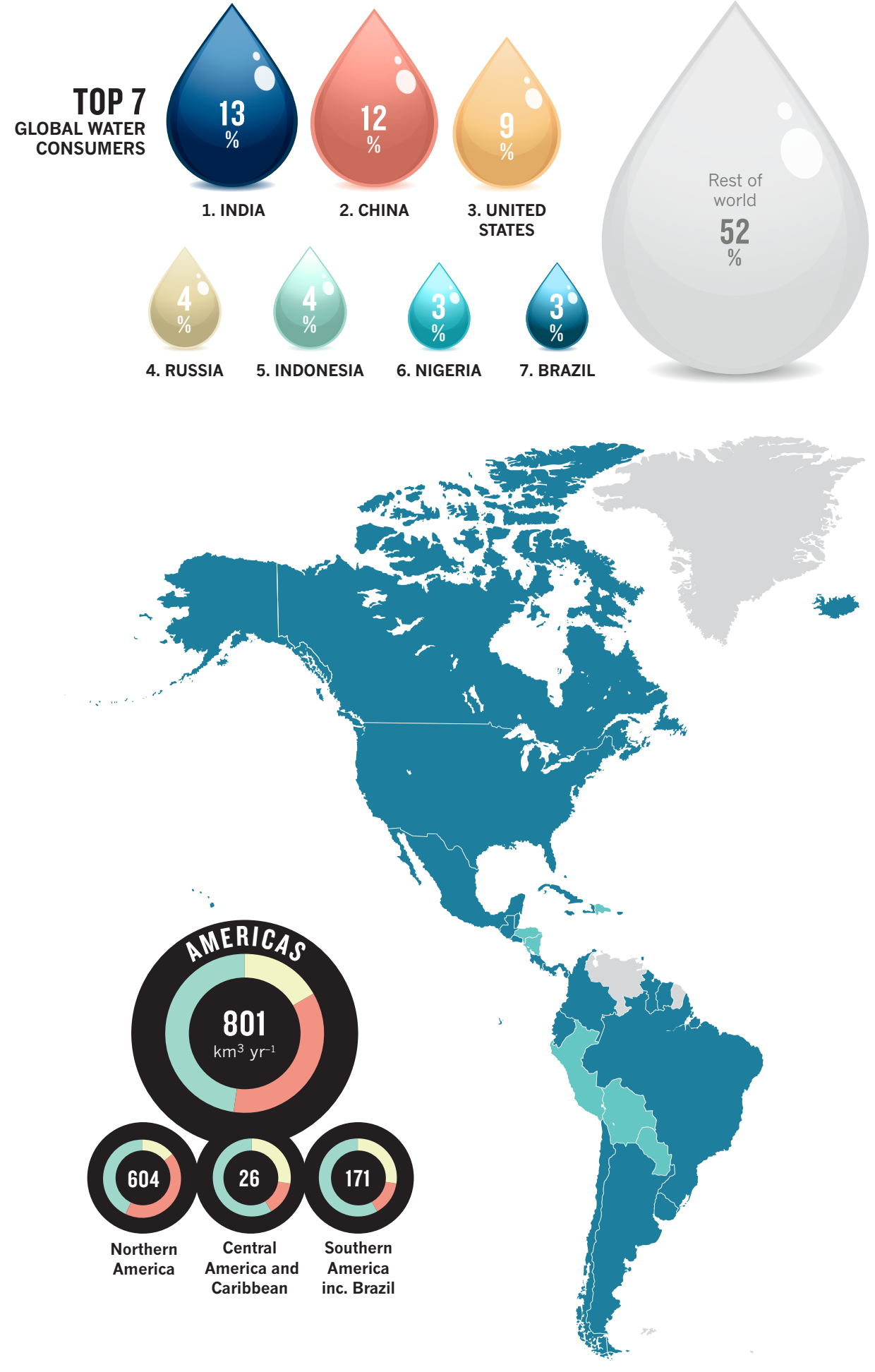


\section{ON THE FARM}

Agriculture consumes almost $70 \%$ of all extracted water. Animal husbandry is the most water-intensive aspect of farming, and causes the greatest disparity in water consumption between the developed and developing worlds.

The United States leads the world in per capita water use attributable to animal products, with each person consuming the equivalent of about $1,200 \mathrm{~m}^{3}$ per year.

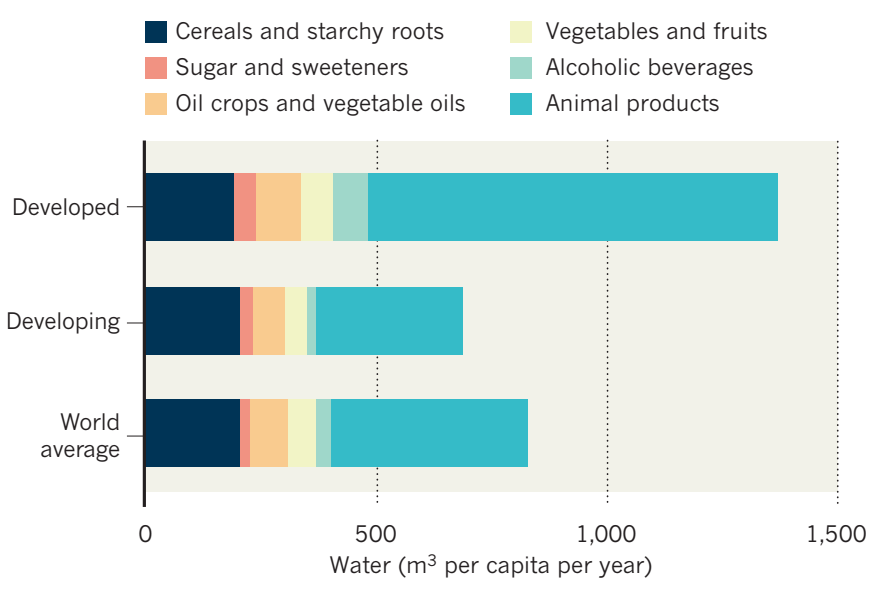

\section{DRILLING DOWN}

Countries are increasingly meeting demand by extracting water from non-renewable underground sources. Groundwater extraction has tripled in the past 50 years. India has had the largest growth, jumping from less than $25 \mathrm{~km}^{3}$ in 1950 to $250 \mathrm{~km}^{3}$ in 2010: about one-quarter of the global total (other countries shown for comparison).

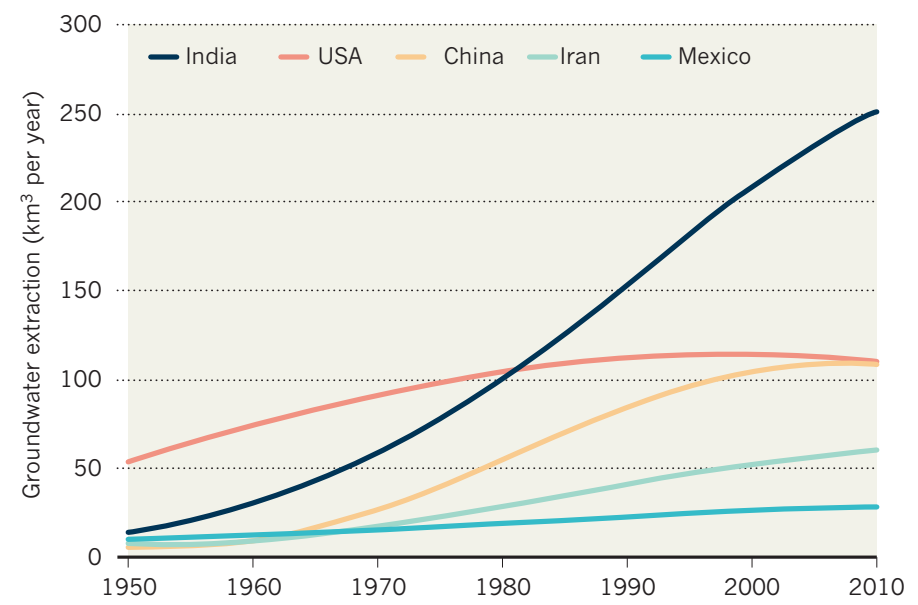

\section{DYING FOR A DRINK}

Nearly 1 billion people have no access to safe and improved water sources such as boreholes, protected wells, springs and rainwater collections. More than $80 \%$ of the world's waste water is not collected or treated, causing millions of deaths from waterborne diarrhoeal diseases every year in the developing world. Urban settlements are the main source of pollution, and the challenge will grow as the world's urban population almost doubles to 6.3 billion by 2050 .

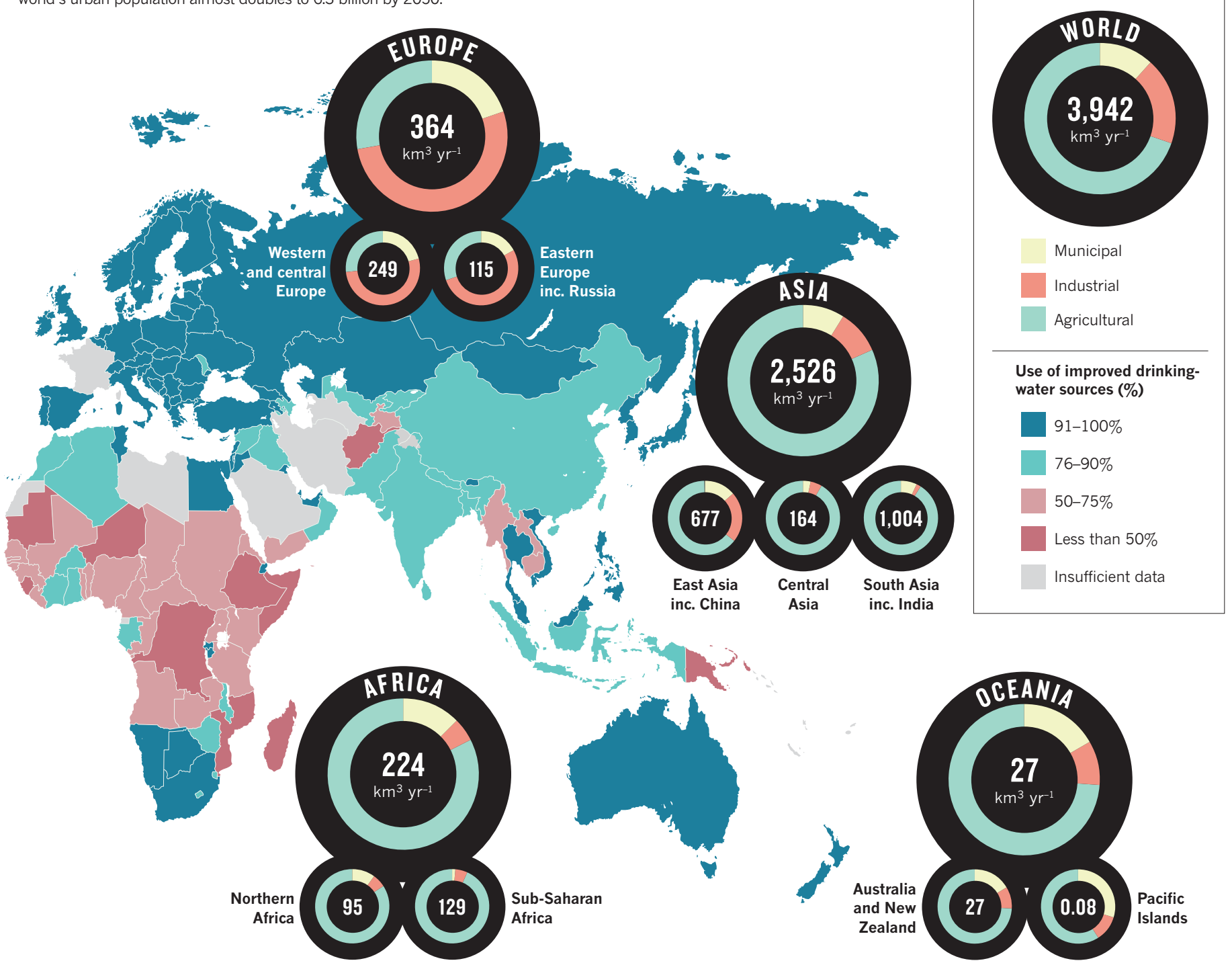

Total withdrawal
by sector

Use of improved drinkingwater sources (\%)

Less than $50 \%$

Insufficient data 